\title{
Correction to: An audit experiment to investigate the "war on cops": a research note
}

\author{
David S. Kirk ${ }^{1} \cdot$ Marti Rovira ${ }^{1}$ \\ Published online: 11 August 2021 \\ (C) Springer Nature B.V. 2021
}

\section{Correction to: Journal of Experimental Criminology https://doi.org/10.1007/s11292-021-09458-x}

In the course of further analysis of the data used in this article, we discovered two data coding mistakes. These mistakes, described below, were not systematically related to treatment assignment in our experiment. Our core inferences and conclusions do not change once correcting the mistakes, although precise numbers reported in the study do change. Accordingly, the corrected figure and tables are included below, and we have uploaded a corrected version of our replication data to Open Science Framework: https://www.osf.io/p8je9/.

The two errors are as follows:

- In our data coding, we failed to exclude several cases from our study in which we did not submit the second of the paired job applications. There were two scenarios by which we did not submit the second job application and the case should have been excluded from the final sample. First, we did not submit the second application if the job posting had been removed from Craigslist or Indeed.com in the hours between when we submitted the first application and when we intended to submit the second. Second, in the case of jobs posted on Indeed.com, we did not submit the second application if we were immediately prompted after the first application to complete an online candidate assessment or to conduct an automated video interview. We inadvertently failed to exclude seven cases from our original

The online version of the original article can be found at https://doi.org/10.1007/s11292-021-09458-x

David S. Kirk

david.kirk@sociology.ox.ac.uk

1 Department of Sociology \& Nuffield College, University of Oxford, 1 New Road, Oxford OX1 $1 \mathrm{NF}, \mathrm{UK}$ 


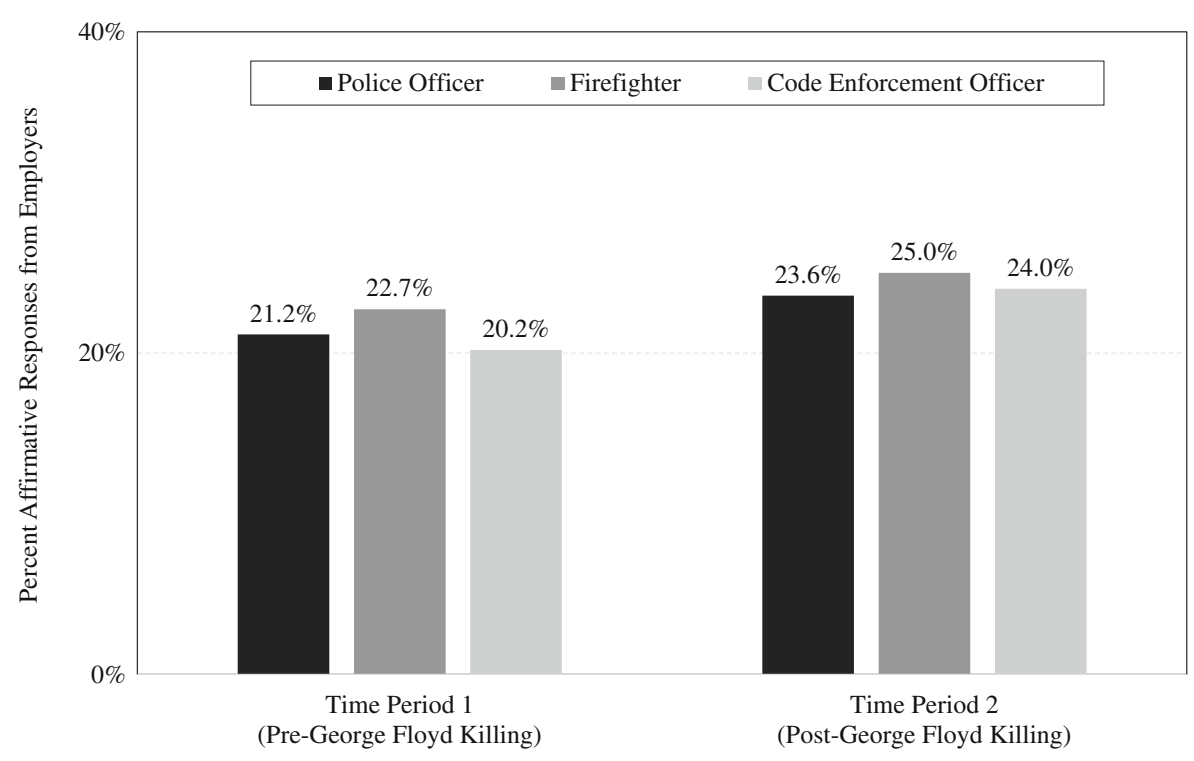

Fig. 1 Percent of Affirmative Employer Responses to Job Applications, by Former Profession and Time Period

analysis that should have been excluded for one of these reasons. The result of this error is that for time period 1 , rather than the initially reported sample of 611 jobs (1222 job applications), our corrected sample consists of 605 jobs (1210 applications). Similarly, for time period 2, rather than a sample of 213 jobs (426 applications), our corrected sample size equals 212 jobs (424 applications).

- For six cases, we incorrectly coded the binary variable for the employer's response as an affirmative response rather than a negative response (i.e., a rejection). Whereas this error leads to slightly lower estimates of the employer response rate to each type of job applicant (see corrected Fig. 1), our core inferences remain the same as in the published article.

Publisher's note Springer Nature remains neutral with regard to jurisdictional claims in published maps and institutional affiliations. 
Table 1. McNemar's Test of the Distribution of Employer Responses by Experimental Condition, Time Period 1 (Pre-George Floyd Killing). A Former Police Officer vs. Former Firefighter. Former Police Officer vs. Former Code Enforcement Officer.

\section{A. Former Police Officer vs. Former Firefighter}

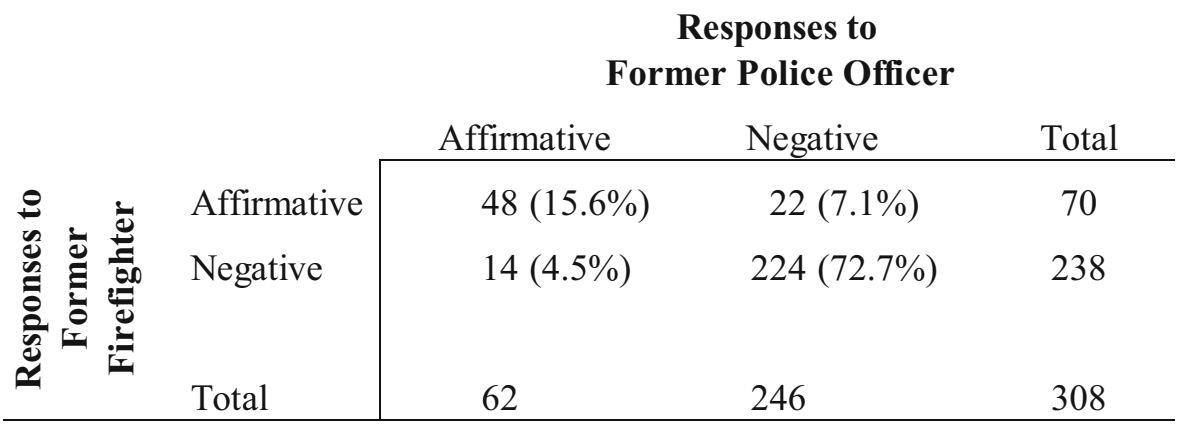

Note: $\chi^{2}=1.78, \mathrm{df}=1, \mathrm{p}$-value $=0.182$

2B. Former Police Officer vs. Former Code Enforcement Officer

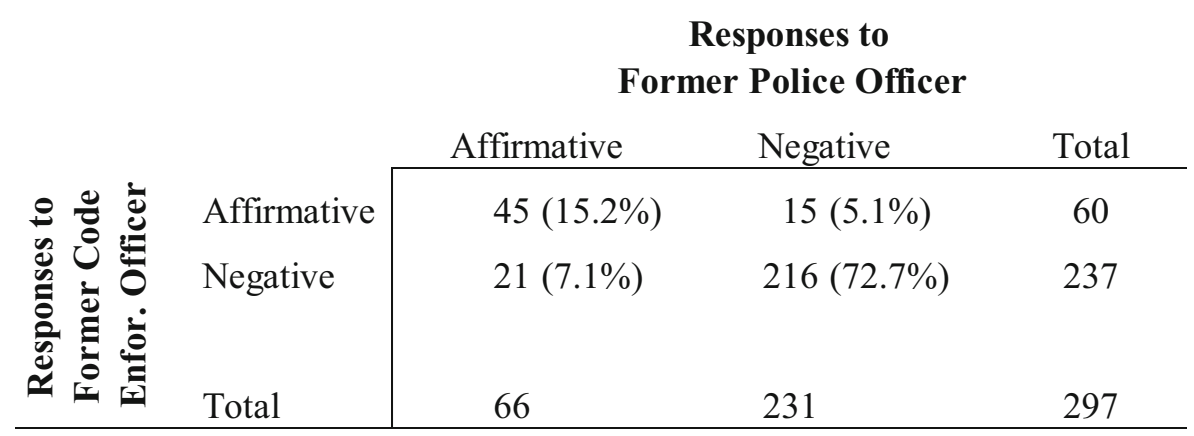

Note: $\chi^{2}=1.00, \mathrm{df}=1, \mathrm{p}$-value $=0.317$ 
Table 2. McNemar's Test of the Distribution of Employer Responses by Experimental Condition, Time Period 2 (Post-George Floyd Killing). A Former Police Officer vs. Former Firefighter. B Former Police Officer vs. Former Code Enforcement Officer.

\section{A. Former Police Officer vs. Former Firefighter}

\begin{tabular}{|c|c|c|c|c|}
\hline & & & $\begin{array}{l}\text { ponses to } \\
\text { Police Office }\end{array}$ & \\
\hline & & Affirmative & Negative & Total \\
\hline & Affirmative & $25(22.3 \%)$ & $3(2.7 \%)$ & 28 \\
\hline$\stackrel{\Xi}{E}$ & Negative & $5(4.5 \%)$ & 79 (70.5\%) & 84 \\
\hline & Total & 30 & 82 & 112 \\
\hline
\end{tabular}

Note: $\chi^{2}=0.50, \mathrm{df}=1, \mathrm{p}$-value $=0.480$

3B. Former Police Officer vs. Former Code Enforcement Officer

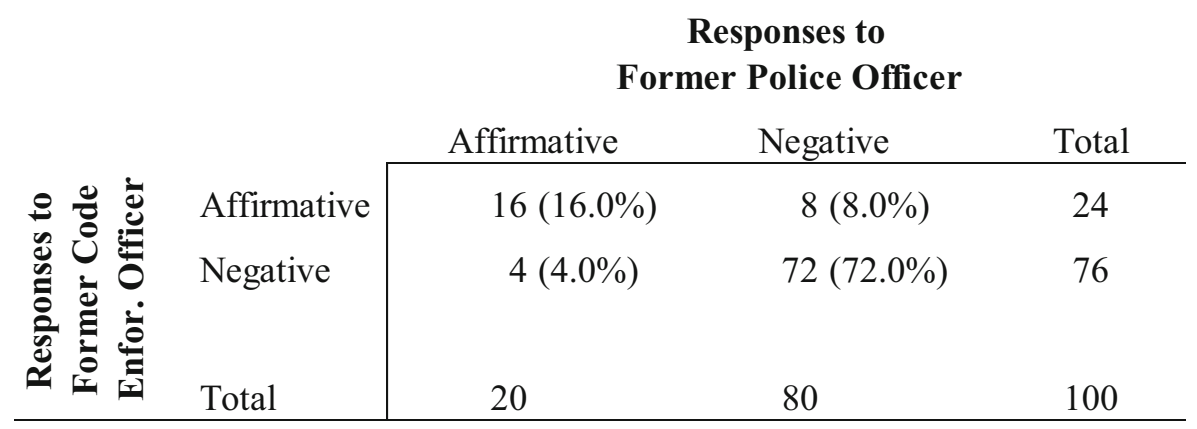

Note: $\chi^{2}=1.33, \mathrm{df}=1, \mathrm{p}$-value $=0.248$ 